\title{
DISCUSSÃO DE ESPECIFICAÇÕES PARA PROJETO DE VIATURA BLINDADA DE COMBATE DE FUZILEIROS
}

\section{DEBATING SPECIFICATIONS FOR DESIGNING AN ARMORED INFANTRY FIGHTING VEHICLE}

\author{
Leonardo Soares Quirino da Silva \\ leosilva@openlink.com.br
}

Orientador: Domício Proença Júnior

Dissertação de mestrado defendida no Programa de Engenharia de Produção da Coppe/UFRJ

\begin{abstract}
Resumo
Essa dissertação discute os parâmetros para o projeto de uma viatura de combate de fuzileiros (VBC-Fzo). A definição das especificações da viatura começou com a análise da necessidade de combinação de infantaria e carros de combate. As formas de cooperação desses dois elementos foram modeladas. Com base ne sse modelo, foram discutidas as vantagens e as características de combate da infantaria equipada com uma viatura blindada específica. A etapa seguinte foi apresentar e discutir as características da VBC-Fzo, bem como problemas ligados à determinação do tamanho e da composição do grupo de combate transportado pela viatura. Na conclusão, foram apresentadas especificações para o projeto de viatura blindada de fuzileiros, com ênfase na mobilidade estratégica aérea.
\end{abstract}

Palavras-chave: Estudos Estratégicos, Ciência Militar, Guerra Blindada, Infantaria Blindada, Infantaria

\begin{abstract}
That dissertation debates the parameters for designing an Armored Infantry Fighting Vehicle (AIFV). The definition of the vehicle specifications begins by studying the need of combining infantry and tanks. Then, a model for that combination is presented. That model is the base for the follow on debate on the advantage of equipping infantry with an armored vehicle of its own, as well as the tactical possibilities that vehicle opens. The next part deals with the aspects of the project of an AIFV, as well as the issues related to the organization and equipment of the squad carried inside the vehicle. In the conclusion, the specifications for the design of an AIFV are presented, emphasizing air strategic mobility.
\end{abstract}

Key words: strategic studies, military science, mechanized warfare, armored infantry, infantry 
O IISS (2002) definiu a VBC-Fzo como sendo veículo de combate levemente blindado, projetado e equipado para transportar um grupo de combate e armado integral/organicamente com armamento de calibre superior a $20 \mathrm{~mm}$. Essa viatura constitui o principal equipamento da infantaria blindada de muitos exércitos.

A missão dessa infantaria é apoiar e proteger os carros de combate (tanques) contra o ataque de infantaria convencional equipada com armas anticarro - lança-rojões ou mísseis -, bem como de sua congênere, além de realizar missões de infantaria convencional quando preciso.

Essa cooperação se faz necessária, em primeiro lugar, em razão da área não visível pela guarnição quando fechada dentro do carro - a zona cega - e por haver uma área não coberta pelo armamento orgânico dos carros - a zona morta - como demonstrado por Simpkin (1980).

A partir daí, investigou-se as formas de combinação da infantaria convencional com os carros de combate. Com base na leitura de Duncan (1949), elaborou-se modelo de cooperação com cinco formas de combinação no ataque e duas na defesa.

O desenvolvimento de viaturas especializadas decorreu da necessidade de que a infantaria blindada tivesse o mesmo grau de mobilidade dos carros e, por razões de custo, grau de proteção suficiente para passar pelo campo batido pelos fogos da artilharia e da infantaria inimigas.

Etterlin (1960) apontou que a experiência de combate na Segunda Guerra Mundial levou ao desenvolvimento de táticas de combate embarcado - quando a infantaria blindada combate de dentro da viatura - e desembarcado - quando, apoiada ou não pela viatura e pelos carros, ela combate como infantaria convencional.

Com base no modelo de combinação para infantaria desembarcada, discutiu-se e elaborou-se modelo específico para o emprego embarcado. 
Ao se definir as características do projeto da VBC-Fzo, tomou-se por base Terry, Jackson et al. (1991), sempre cotejado com Ogorkiewicz (1991), que sugerem que o projeto de viaturas blindadas deve ser orientado por seis parâmetros:

- mobilidade, que nessa dissertação foi dividida em estratégica, operacional e tática;

- poder de fogo, composto pelos sistemas de armas e os sistemas de informações do campo de batalha (battlefield management systems);

- survivabilidade (survivability), dada pelos sistemas de proteção passivos (blindagem, camuflagem, características de projeto, engodos) e pelos sistemas de proteção ativos, que visam destruir a munição antes que ela atinja a viatura;

- capacidade de transporte, que se refere ao número de soldados e ao material embarcado;

- combatabilidade (fightability), que trata da ergonomia da viatura com vistas a garantir que o nível de conforto e a facilidade de uso não comprometam a capacidade de combate dos soldados ou até mesmo a melhore, e

- disponibilidade (availability), que trata da confiabilidade do equipamento o que, nessa dissertação, foi chamado de logística.

Dentro ainda dessa parte do trabalho, discutiu-se mais pormenorizadamente o tamanho e o armamento do grupo de combate a ser transportado pela viatura.

Nessa parte do trabalho foi apresentada literatura sobre a experiência de combate e o desenvolvimento de viaturas semelhantes em outros exércitos, sendo de especial relevância Haworth (1999), bem como publicações técnicas e manuais de campanha do exército dos EUA.

$\mathrm{Na}$ conclusão, procurou-se definir os requisitos operacionais básicos para uma VBCFzo a ser usada pelo exército brasileiro. $\mathrm{Na}$ falta de uma política de defesa declaratória no Brasil, tomou-se por base Brigagão\&ProençaJr (2002) que defendem que as forças armadas 
brasileiras devem ter o mesmo grau de modernidade e prontidão que as forças da Otan. Como os veículos que estão sendo projetados para as principais forças da organização possuem mobilidade aérea estratégica, esse foi o parâmetro que determinou as escolhas que se seguiram.

Como se vê, a dissertação tratou de tema de importância capital, a defesa nacional. Por essa razão, ao se discutir aspectos ligados à mobilidade, buscou-se dados referentes à infraestrutura de transporte rodoviário, ferroviário e aéreo, visto que a literatura compulsada apresentava parâmetros referentes aos recursos disponíveis na Europa ocidental e nos EUA.

Ao tratar da discussão sobre mobilidade, discordou-se de Terry, Jackson et al. (1991) e de Orgokiewiecz (1991) ao se chamar de mobilidade tática o que ambos os autores chamam de mobilidade no campo de batalha (battlefield mobility), o deslocamento sob fogo inimigo, logo em um enfrentamento. Essa discordância baseou-se na leitura de Clausewitz (1993), que entende o nível tático como o uso da força nos enfrentamentos. Por extensão, o grau de mobilidade de uma viatura quando em combate é a mobilidade tática.

Ainda tendo por base a teoria clausewitziana, sugere-se a supressão da mobilidade operacional e o estudo para incorporar as características a ela atribuídas nas mobilidades tática e estratégica. Cabe observar que as características apontadas tanto na mobilidade tática de Terry, Jackson et al. (1991) quanto na mobilidade operacional de Orgokiewicz (1991) são idênticas e ora são cobertas pelo que eles mesmos chamam de mobilidade estratégica e de mobilidade de campo de batalha.

Essa dissertação também supriu lacuna sobre o tema subjacente às especificações da viatura, o da infantaria blindada. Os dois únicos livros encontrados a tratar diretamente o assunto foram Etterlin (1961) e Simpkin (1980).

Neste particular, o modelo com as diferentes formas de combinação de infantaria e carros de combate e sua aplicação para o combate embarcado e desembarcado são uma contribuição original para a discussão no campo.

Referências: 
BRIGAGÃO, Clóvis, PROENÇA JÚNIOR, Domício, 2002, Concertação múltipla: inserção internacional de segurança do Brasil, Rio de Janeiro, Konrad Adenauer Stiftung e Livraria Francisco Alves Editora Limitada.

CLAUSEWITZ, Carl von, 1993, On War, 5a edição da tradução para o inglês de HOWARD, Michael e PARET, Peter, Nova Iorque e Toronto, Alfred A. Knopf Incorporated.

DOA (Department Of the Army), 1985, Field Manual 7-7 Mechanized Infantry Platoon and Squad (APC), Headquarters, Department of the Army, Washington.

DOA (Department Of the Army), 1991, Field Manual 71-1 Tank and Mechanized Infantry Company Team, Headquarters, Department of the Army, Washington.

DOA (Department Of the Army), 1993b, Field Manual 7-7J Mechanized Infantry squad and platoon (Bradley), Headquarters, Department of the Army, Washington.

DOA (Department Of The Army), 1994b, FM 23-25 Light antiarmor weapons, Headquarters, Department of the Army, Washington.

DOA (Department Of the Army), 1994c, Field Manual 17-12-8 Light Cavalry Gunnery, Headquarters, Department of the Army, Washington.

DOA (Department Of the Army), 1998, Field Manual 71-1 Tank And Mechanized Infantry Company Team, Headquarters, Department of the Army, Washington.

DOA (Department Of the Army), 2002a, Field Manual 3-06.11 Combined Arms Operations In Urban Terrain, Headquarters, Department of the Army, Washington. Acessado no site www.globalsecurity.org/military/library/policy/army/fm/3-06.11/index.html às 15h45 de $31 / 03 / 2004$.

DOA (Department Of the Army), 2002b, Field Manual 3-21.71 Mechanized Infantry platoon and squad (Bradley), Headquarters, Department of the Army, Washington. Acessado no site www.globalsecurity.org/military/library/policy/army/fm/3-21-71/index.html às $15 \mathrm{~h} 45$ de $31 / 03 / 2004$. 
DOA (Department Of the Army), 2002c, Field Manual 20-32 Mine/Counter-mine Operations

Change 3 (october), Headquarters, Department of the Army, Washington.

DOA (Department Of the Army), 2003, Field Manual 3-22.1 Bradley Gunnery, Headquarters, Department of the Army, Washington

DOA (Department Of the Army), 2004, Future combat system primer, Headquarters, Department of the Army, Washington.

DUNCAN, William D., 1949, "Os Carros de combate da DI". In: Military Review, edição em português, junho, pp 45-51.

GUDERIAN, Heinz, 1998, Achtung - Panzer! The development of armoured forces and opertional potential, traduzido para o inglês por DUFFY, Christopher e com introdução e notas HARRIS, Paul, Londres, Arms\&Armour Press.

HAWORTH, W. Blair, 1999, The Bradley and how it got that way: technology, instituitions, and the problem of mechanized infantry in the United States Army, $1^{\mathrm{a}}$ ed. Westport, London, Greenwood Press.

IISS (The International Institute of Strategic Studies), 2002, Military Balance 2002-2003, Londres, Oxford University Press.

ORGOKIEWICZ, Richard M., 1991, Technology of tanks II, Coulsdon, Jane’s Information Group Limited.

ETTERLIN, Fridolin von Senger und, 1961, Die Panzergrenadiere, Munique, J. F. Lehmanns Verlag.

SIMPKIN, Richard E, 1980, Mechanized Infantry, Oxford, Brassey`s Publishers Limited.

TERRY, T. W., JACKSON, S. R., JONES, B. E. et al., 1991, Fighting Vehicles, 1a edição, Londres, Brassey's (UK) Ltd. 
Recebido em 10/06/05 e aceito para publicação em 25/06/05. 